\title{
Specific alterations in the serum amino acid profile of patients with lung cancer and head and neck cancer
}

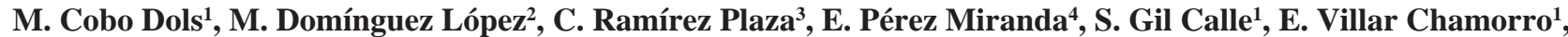 \\ I. Alés Díaz ${ }^{1}$, A. Montesa Pino ${ }^{1}$, J. Alcaide García ${ }^{1}$, V. Gutiérrez Calderón ${ }^{1}$
}

\section{Summary}

Purpose: Metabolism of the immediate principles is altered in cancer patients, resulting in an altered serum concentration of amino acids. The aim of this study was to find specific serum amino acid profiles in patients with cancer of the lung or head and neck.

Material and methods: We analyzed the baseline serum levels of 27 amino acids in 51 patients with cancer of the lung or head and neck with no metabolic alterations or other concomitant disorders and compared the results with a control group.

Results: Compared with the control group, patients with head cancer had significant differences in cysteine, aspartic acid, 3-methyl histidine, alanine, glycine, lysine, methionine, proline, serine, taurine, tyrosine, and threonine; and patients with lung cancer in cysteine, aspartic acid, 3-methyl histidine, histidine, citrulline, ornithine, alanine, glycine, lysine, methionine, proline, serine, taurine, tyrosine, and threonine.

Conclusions: Variation in serum levels of certain amino acids in head and neck cancer and lung cancer is probably caused by interaction of the neoplasm with the protein metabolism. Each type of tumor has a certain specificity in the serum amino acid profile that may be useful in the diagnosis of these tumors.

Key words:

Amino acids. Lung cancer. Head and neck cancer

Oncología, 2006; 29 (7):283-290

\footnotetext{
${ }^{1}$ Servicio de Oncología Médica

${ }^{2}$ Servicio de Endocrinología y Nutrición

${ }^{3}$ Servicio de Cirugía General y Digestiva

${ }^{4}$ Servicio de Laboratorio y Análisis Clínicos

Hospital Regional Universitario Carlos Haya

Málaga (España)
}

Recibido: 28.03 .06

Aceptado: 07.04.06 


\section{Resumen}

Objetivo: El metabolismo de los principios inmediatos está alterado en el enfermo neoplásico, lo que se traduce en una concentración de aminoácidos séricos alterada. El objetivo del estudio es encontrar perfiles específicos de aminoácidos séricos en cáncer de pulmón y de cabeza y cuello.

Material y métodos: En 51 pacientes con carcinoma de pulmón y cabeza y cuello sin alteraciones metabólicas ni otras patologías concomitantes se analizan los niveles séricos basales de 27 aminoácidos diferentes y se comparan entre ellos y con un grupo control.

Resultados: Se encontraron diferencias estadísticamente significativas en pacientes con cáncer de cabeza respecto al grupo control en: cistina, ácido aspártico, 3-metil-histidina, alanina, glicina, lisina, metionina, prolina, serina, taurina, tirosina, treonina. Y en pacientes con cáncer de pulmón en: cistina, ácido aspártico, 3-metil-histidina, histidina, citrulina, ornitina, alanina, glicina, lisina, metionina, prolina, serina, taurina, tirosina, treonina.

Conclusiones: La variación en los niveles séricos de determinados aminoácidos en cáncer de cabeza y cuello y en cáncer de pulmón está motivado probablemente por la interacción de la neoplasia en el metabolismo proteico del huésped. En cada tipo de tumor hay una cierta especificidad en el perfil de aminoácidos séricos que puede tener utilidad en el diagnóstico de estos tumores

Palabras clave: Aminoácidos. Cáncer pulmón. Cáncer cabeza y cuello.

\section{Introduction}

Amino acids are simple, monomeric subunits that provide the key to the structure of thousands of different proteins. They are composed of a carboxyl group and an amino group, bound to a carbon atom $^{1}$. The 20 amino acids in proteins are usually referred to as standard ${ }^{2}$. Besides the 20 standard amino acids that are common to all proteins, other amino acids have been detected that are only found in certain specific proteins. Five main groups of amino acids exist: the non-polar aliphatic R-groups, the aromatic, the polar with no charge, the negatively charged, and the positively charged ${ }^{3}$. Ion exchange chromatography is the most commonly used technique for the separation, identification and quantification of each of the amino acids present in a mixture ${ }^{4}$.

Certain metabolic and thermodynamic processes take place in the cancer patient that are advantageous compared with the normal cell, and with which metabolism of the immediate principles has special peculiarities, not only with carbohydrates ${ }^{5}$ and fats ${ }^{6}$, but also with proteins. Patients with cancer and cachexia have a reduced protein synthesis and altered glucose metabolism at the level of the skeletal muscle, which has been associated with a reduction in the uptake of leucine by the muscle ${ }^{7}$.

Alterations in the metabolism of amino acids and proteins in persons with neoplasms are usually the consequence of certain dysfunctions in the host metabolism, such as accelerated glyconeogenesis and increased protein synthesis by the liver ${ }^{8}$. As a result, changes in the serum profile of free amino acids are reflected in alterations in protein metabolism, as occurs in other diseases, such as diabetic ketoacidosis and protein or calorie malnutrition ${ }^{9}$. The degree of modification of the amino acid pattern in cancer patients depends on such variables as the specific type of tumor, the stage of the disease and its extension, as well as the possible association of protein-calorie malnutrition ${ }^{10}$.

Tumors in different organs can differ greatly, not only in their capacity for proliferation and metastasis, but also in the influence on the host metabolic status ${ }^{11}$ and, consequently, in changes in the serum 
amino acid profile in relation to the type of tumor. Increased levels have been detected for amino acids that have certain specificities in relation to the specific type of tumor, like sarcomas ${ }^{12}$, hepatomas ${ }^{13}$, lung ${ }^{14}$, breast ${ }^{15}$, head and neck region ${ }^{16}$, gastrointestinal $^{17}$, and bladder ${ }^{18}$. Other studies have shown that these amino acids return to their usual values after effective therapy, and in turn rise again when the disease relapses ${ }^{19,20}$.

The aim of our study was to analyze the serum amino acids in patients with head and neck cancer and in patients with advanced lung cancer, not in the surgical period, with no nutritional alterations or other accompanying disorders, and to compare these levels with those of a healthy control group in order to try to detect specific patterns of amino acids in these two types of tumors.

\section{Material and methods}

\section{Patient selection}

This prospective study included 51 patients with head and neck cancer or lung cancer, not in the surgical period, treated by our Medical Oncology Service. The control group consisted of 26 healthy subjects without cancer or intercurrent diseases to determine the amino acid profile.

The inclusion criteria were: age 18-70 years; ECOG $<2$; weight loss less than $5 \%$; advanced stage not in the surgical; no prior chemotherapy; no endocrinologic or metabolic disorders; no uncontrolled hypertension or infections; normal liver, heart and kidney function; and adequate bone marrow reserve. The inclusion criteria for the control group were: adults aged 18-70 years, good general state of health, normal nutritional and daily regimen, no intercurrent acute or chronic disease.

The nutritional index was assessed from clinical and laboratory data. Patients were only included if their weight loss was less than $5 \%$ between onset of the first symptoms of the neoplastic disease and the time of inclusion in the study. This was in order to minimize the effect of tumor cachexia on the host metabolism, and avoid its influence on the serum amino acid profile. The intercurrent diseases that were avoided were those we believed might interfere in the amino acid levels: acute stressful condi- tions for the organism, such as infections; diabetes mellitus; other endocrinologic or metabolic alterations; uncontrolled hypertension; liver, cardiac, or kidney disease; chronic infectious diseases, such as hepatitis B or C, or AIDS.

\section{Laboratory measurements}

The measurements consisted of the serum analysis of 27 different amino acids. The amino acids measured were: aspartic acid, taurine, threonine, serine, asparaginine, glutamic acid, glutamine, proline, glycine, alanine, citrulline, aminobutyric acid, valine, cysteine, methionine, isoleucine, leucine, tyrosine, phenylalanine, tryptophan, ornithine, lysine, histidine, arginine, hydroxyproline, 3-methyl histidine, 1 methyl histidine. Measurements were made with a Beckman System 6300/7300 Amino Acid Analyzer (Pickering Laboratories) according to the manufacturer's instructions and protocols. Samples for analysis were prepared from $1 \mathrm{ml}$ of blood collected into tubes containing heparin. An aliquot $(20 \mu \mathrm{L})$ of whole blood was transferred to a $400 \mu \mathrm{L}$ centrifuge tube and $200 \mu \mathrm{L}$ of a buffer solution $(\mathrm{pH}$ 2.2 containing a mixture of hydrochloric acid and citric acid), mixed thoroughly, frozen and stored at $-20^{\circ} \mathrm{C}$ for batched analysis to minimize methodological variation in measurement. Subsequently, the samples were thawed and centrifuged at $13,000 \mathrm{rpm}$ for $10 \mathrm{~min}$. To de-proteinase the sample, $200 \mu \mathrm{L}$ of the supernatant was taken with a micropipette, transferred to a 400 (L centrifuge tube to which $20 \mu \mathrm{L}$ of sulphosalicylic acid was added and centrifuged at 13,000 rpm for $5 \mathrm{~min}$. The supernatant $(5 \mu \mathrm{L})$ was mixed with $50 \%$ Li-A (Lithium citrate high performance amino acid analysis buffer) and passed through a $2 \mu \mathrm{L}$ filter.

\section{Statistical analyses}

For the descriptive study, the normality of the distribution of the amino acids and the other parameters in blood and urine in each one of the cycles was verified with the Kolgomorov-Smirnoff test. The description was made with the mean \pm standard deviation for the parameters that followed a normal distribution, and the median and 25 and 75 percentiles for the variables that did not follow a normal distribution. The Kruskall-Wallis test was used to 
compare the baseline levels of each of the amino acids collected in blood and urine from the cancer patients with those of the healthy controls (polychotomised independent variable and quantitative dependent variable, with independent samples).

\section{Results}

The median age of the patients was 58 (range, 23$70)$, with 48 men $(88 \%)$ and six women (12\%). The median age of the controls, all of whom were men, was 53 years (range, 40-66). Regarding tumor location, 27 patients $(50 \%)$ had epidermoid head and neck carcinoma and 24 (44.4\%) had lung cancer, 17 (70\%) with small cell lung cancer and seven (30\%) with non-small cell lung cancer. Of the patients with head and neck tumors, all were locally advanced, non resectable, stage IV tumors, of which just seven $(25 \%)$ had received no prior treatment, with the others $(75 \%)$ having been treated with surgery or radiotherapy, or both. Among the lung cancer patients, all the small cell lung cancer patients had chest limited disease whereas of the patients with non-small cell lung cancer, two were stage IV (one with intrapulmonary and the other with supraclavicular metastasis) and five patients were stage IIIb (three after progression with radiotherapy).

Concerning the comparative analysis of the serum amino acid levels in lung cancer patients, head and neck cancer patients, and the control group, the concentration of amino acids in blood was determined in $\mu \mathrm{M} / \mathrm{L}$ (Table I). Analysis of the baseline serum amino acid levels in each of the tumors and in the control group showed no significant differences between the different types of tumor for any of the

TABLE I

Baseline serum levels of amino acids (mean \pm standard deviation, except for the first six which did not follow a normal distribution, with the median and 25-75 percentiles) in patients with head and neck cancer (Group 1), lung cancer (Group 2) and healthy subjects (Group 3), and intergroup comparisons

\begin{tabular}{|c|c|c|c|c|c|}
\hline Amino acid & $\begin{array}{c}\text { Head and neck cancer } \\
\text { (Group 1) }\end{array}$ & $\begin{array}{l}\text { Lung cancer } \\
\text { (Group 2) }\end{array}$ & $\begin{array}{l}\text { Healthy subjects } \\
\text { (Group 3) }\end{array}$ & $\begin{array}{l}\text { Group } 1 \text { vs. } \\
\text { Group } 3\end{array}$ & $\begin{array}{l}\text { Group } 2 \text { vs. } \\
\text { Group } 3\end{array}$ \\
\hline 3-methyl histidine & $53(14-95)$ & $1(1-1)$ & $1(1-1)$ & 0.0001 & 0.0001 \\
\hline Aminobutyrate & $2(2-17)$ & $14(2-20)$ & $6(2-21)$ & NS & NS \\
\hline Aspartic acid & $7(3-12)$ & $2(1-4)$ & $1(1-4)$ & 0.0001 & 0.0001 \\
\hline Hydroxyproline & $1(1-1)$ & $1(1-1)$ & 1(1-1) & NS & NS \\
\hline Cysteine & $20(12-30)$ & $37(27-43)$ & $37(24-40)$ & 0.018 & 0.03 \\
\hline Alanine & $222.7 \pm 81$ & $311.9 \pm 93.8$ & $343 \pm 109$ & 0.004 & 0.0001 \\
\hline Arginine & $75.2 \pm 36.1$ & $83.7 \pm 40.9$ & $81.8 \pm 39.7$ & NS & NS \\
\hline Asparagine & $33.4 \pm 20.8$ & $38.1 \pm 21.3$ & $38.9 \pm 22.2$ & NS & NS \\
\hline Citrulline & $14.5 \pm 7.4$ & $24.2 \pm 11.2$ & $28.12 \pm 17.2$ & NS & 0.03 \\
\hline Phenylalanine & $56.5 \pm 23.2$ & $66.4 \pm 22.7$ & $66.4 \pm 17$ & NS & NS \\
\hline Glycine & $161 \pm 60.8$ & $243 \pm 101.9$ & $239 \pm 71.2$ & 0.001 & 0.003 \\
\hline Glutamine & $679.6 \pm 124.6$ & $692.88 \pm 177.9$ & $733.5 \pm 139.2$ & NS & NS \\
\hline Histidine & $150.2 \pm 70.8$ & $99.3 \pm 53.6$ & $76.4 \pm 42.8$ & NS & 0.004 \\
\hline Isoleucine & $54.6 \pm 28.1$ & $62.5 \pm 20.9$ & $69.3 \pm 17.8$ & NS & NS \\
\hline Leucine & $116.1 \pm 54.6$ & $129.9 \pm 50.1$ & $132.7 \pm 35$ & NS & NS \\
\hline Lysine & $279.5 \pm 96$ & $174.6 \pm 127.8$ & $169.4 \pm 66.8$ & 0.003 & 0.002 \\
\hline Methionine & $16.1 \pm 1.5$ & $27.3 \pm 15.7$ & $30.3 \pm 15.03$ & 0.02 & 0.002 \\
\hline Glutamic acid & $50.4 \pm 33.1$ & $65.3 \pm 33.3$ & $67.3 \pm 28.7$ & NS & NS \\
\hline Ornithine & $141.2 \pm 64.1$ & $107 \pm 61.9$ & $99 \pm 51$ & NS & 0.04 \\
\hline Proline & $115.1 \pm 44.2$ & $189.6 \pm 57.1$ & $240.3 \pm 121$ & 0.005 & 0.0001 \\
\hline Serine & $76.6 \pm 37.6$ & $111 \pm 66$ & $108.3 \pm 26$ & 0.03 & 0.04 \\
\hline Taurine & $31.4 \pm 19.2$ & $57.2 \pm 29.6$ & $59.5 \pm 40$ & 0.02 & 0.01 \\
\hline Tyrosine & $54.2 \pm 23.7$ & $70.5 \pm 28.6$ & $74.7 \pm 18.1$ & 0.04 & 0.01 \\
\hline Threonine & $96.4 \pm 40.9$ & $127 \pm 42.4$ & $126 \pm 40.6$ & 0.031 & 0.038 \\
\hline Tryptophan & $59.6 \pm 26.5$ & $52.2 \pm 22$ & $59.4 \pm 18.7$ & NS & NS \\
\hline Valine & $189.2 \pm 79.9$ & $226.5 \pm 83.3$ & $234.9 \pm 72.8$ & NS & NS \\
\hline
\end{tabular}


amino acids. However, comparison of the amino acids between the cancer patients and the healthy subjects showed differences in an important number of specific amino acids. In general, the mean serum concentration of the amino acids was higher in all the types of tumors studied in comparison with the normal population, except for six amino acids: 3methyl histidine, aspartic acid, histidine, lysine, ornithine and aminobutyric acid.

Significant differences were seen in patients with head and neck cancer as compared with the control group in the following amino acids: cystine, aspartic acid, 3-methyl histidine, alanine, glycine, lysine, methionine, proline, serine, taurine, tyrosine, and treonine. Significant differences were seen in the patients with lung cancer, as compared with the control group, in cystine, aspartic acid, 3-methyl histidine, histidine, citrulline, ornithine, alanine, glycine, lysine, methionine, proline, serine, taurine, tyrosine, and treonine (Table I).

\section{Discussion}

After it was learnt that the presence of a tumor resulted in increased protein metabolism, ${ }^{21}$ studies were undertaken on variations in serum levels of amino acids as possible indicators of the influence of the tumor on the host proteins, as well as which amino acids preferably require a neoplasm for protein synthesis ${ }^{22}$. In our study, we found that in patients with one of the two types of tumors studied (lung cancer and head and neck cancer), the baseline serum levels of a series of amino acids were significantly different when compared with a healthy control group. Thus, the presence of a tumor that "parasitizes" the organism may have a decisive influence on its general metabolism, and more specifically on its protein metabolism, which would affect the serum concentration of amino acids, which usually constitute about $0.5 \%$ of the whole pool of amino acids in a person weighting $70 \mathrm{~kg}^{23}$. Free amino acids serve as a substrate for protein synthesis, glyconeogenesis, ureagenesis and other catabolic processes. Accordingly, it is logical to suppose, as has been demonstrated, that in both cancer and other diseases involving an imbalance in this metabolic order, alterations take place in serum levels of amino acids? .
It should be recalled that tumors in different organs vary not only in their capacity for proliferation and dissemination, but also in their influence on host metabolism ${ }^{11}$ and, possibly, in the specific amino acid profile with relation to the histopathologic lineage of the neoplasm. The interdependence of their relationship was confirmed on verifying that they are normalized when tumor therapy is effective, and return to high levels if the neoplastic process recurs ${ }^{19}$.

In cancer, the serum concentration of amino acids is conditioned by imbalances in protein metabolism induced both by host-tumor interaction and by the metabolic requirements of the tumor for specific amino acids. Moreover, changes in the serum amino acid profile have been used to attempt to configure diagnostic and prognostic patterns for each type of tumor, as has been done for other diseases ${ }^{9}$. Nevertheless, although changes in the amino acid profile occur, changes which have a certain specificity in cancers, we should consider the multiple factors that influence their concentration and the reduced homogeneity of the tumors studied in most reports, assuming that a specific change in the serum amino acid concentration can be attributed to the tumor ${ }^{24}$. Modifications in the amino acid pattern depend on such variables as the specific type of tumor, the stage of the disease and its extension, and its association or otherwise with protein and calorie malnutrition. This all suggests that further studies are required, with neoplasms in early stages, or more advanced stages of extraintestinal tumors, with a longitudinal design, to define more precisely the deficit or excess of amino acids in cancer.

In our study, we attempted to define the influence of head and neck tumors and lung tumors on the protein metabolism of the patients involved. In order to avoid the bias mentioned above, we attempted to homogenize the selection criteria for our sample as much as possible. As all the patients had an adequate nutritional status and a normal lifestyle, neither a sedentary lifestyle, nor changes in nutritional habits influenced the results. Although not all the patients were in the early disease stages, none had suffered a weight loss greater than $5 \%$ since the onset of symptoms. Moreover, none had infectious, endocrinologic, kidney, or liver disorders, situations which cause the serum concentration of amino acids to vary. The other influencing factors, such as tumor 
load, we tried to homogenize, choosing patients with a low tumor load in similar stages, locally advanced and with no disseminated metastases. The age of the patients was also similar, as they were all over 40 years of age, whatever their type of tumor. The control group was composed of healthy persons, with no acute or chronic disease, and with the same nutritional and lifestyle habits as the cancer patients. Their age distribution was similar, and all were men, as only six of the 51 cancer patients were women.

Comparison of the patients with the controls showed changes in the following amino acids in both types of tumor: cystine, aspartic acid, 3-methyl histidine, alanine, glycine, methionine, proline, serine, taurine, tyrosine, treonine. Citrulline, histidine, lysine and ornithine were also significantly changed in lung cancer patients.

Patients with a nutritional deficit or in a state of cachexia have a generalized reduction in most amino acids, especially the precursors of neoglycogenesis, due to the increased use of these to obtain energy ${ }^{8}$. However, the cancer patients in our series, with no weight loss or nutritional deficit, had an increased amino acid profile compared with the controls, except for aspartic acid, 3-methyl histidine, lysine, histidine and ornithine, the concentrations of which were reduced in lung cancer patients, and aspartic acid and 3-methyl histidine in head and neck cancer patients.

Some studies have analyzed changes in certain amino acids in each type of tumor, in order to determine the influence of a particular tumor on the general metabolism of the patient, and occasionally to use as a diagnostic and therapeutic parameter ${ }^{12-18}$. Most of these studies, however, have included a low number of patients, with notable variations in their weight, clinical situation, tumor stage, and so on, all of which affect their reliability.

Two studies of patients with head and neck cancers failed to detect significantly high levels of any amino acid ${ }^{19,25}$, whereas they did detect a reduction in the levels of treonine or glycine. This latter is a neoglycogenic amino acid, which in our series was high in comparison with the controls. Fewer amino acids were studied in these two works than in our series, with few patients and with a very reduced energy intake due to tumor invasion and difficulty swallowing. A greater number of studies have been done in lung cancer patients, but the same problems are still found regarding variability of essential factors when interpreting the results. In fact, little homogeneity exists between the studies in their results, and there are even discrepancies.

Cascino $^{15}$ reported a reduction in glycogenic amino acids in lung cancer patients with an acceptable nutritional status and an increase in tryptophan and glutamic acid compared with controls, suggesting that in this type of tumor there exists a certain situation of hypercatabolism preceding the cachexia. We failed to detect any of these changes in our series. The results of this study are coherent, since, although no patient was in an advanced state of cachexia, neither the degree of tumor extension nor individual weight loss were recorded. What does seem clear is that a limit is reached during the course of cancer at which host metabolic disturbances are so intense (regarding total body protein exchange) that they cause a reduction in nitrogen balance, which is the starting point for impoverishment, though no objective nutritional deficit is detected till some time later.

Increases are detected in a series of serum amino acids in microcytic lung cancer. These increases have been attributed to specific features of this type of tumor, independently of the nutritional status of the subject ${ }^{14}$. This study has similarities to our series regarding increases in blood of an important number of amino acids, although there are specific differences between the different amino acids that experience an increase, probably due to bias and differences in patients selection.

A study undertaken in murine models with lung cancer implants found increases in almost the same amino acids as those that were increased in our study; only glycine and taurine were unchanged in rats $^{26}$, whereas they were increased in our study. In both studies, murine and human, the constants were strictly controlled to avoid any skew. Even though we were unable to ensure that all the constants were homogenous, the results are similar to those of the murine study. This latter study evaluated the interference in the host protein metabolism of a recently implanted tumor, with no other concurrent modifying factors.

Another important finding is that the histopathologic types of the tumors studied, lung and head and neck, underwent similar changes in their amino acid 
profiles, such that, with the exception of citrulline, the other eight amino acids that were significantly raised in the lung cancer patients were also raised in the head and neck cancer patients. The only difference was that three of the five amino acids whose levels were lower in the lung cancer patients (ornithine, lysine, and histidine) were normal in the head and neck cancer patients, though comparison between the two groups of cancer patients studied showed no significant differences for any of the amino acids analyzed. We are unaware of the reasons why these and not other amino acids suffer changes in these tumors, and in determinate stages. In our series we were able to establish that, in the absence of changes in nutritional status, the serum levels of various amino acids tended to increase during certain stages of these two types of tumor. Verification of similar changes in both groups could indicate that either both types of neoplasm have a very similar effect on metabolism, or that in the cancer patient the interferences in protein metabolism are correlated more with the evolutionary stage of the tumor rather than its histological lineage. A more extensive, precise and specific evolutionary analysis might provide information about the changes in the amino acids during the different stages and their possible association with the clinical and nutritional status of the patient. This would then enable predictive clinical models to be established based on temporal variations in the profile of serum amino acids.

\footnotetext{
Correspondence:

M. Cobo-Dols, MD

Sección de Oncología Médica

Pabellón A, $3^{\circ}$ planta Derecha

Secretaría de Oncología Médica

Hospital Regional Universitario Carlos Haya

Avda. Carlos Haya

E-29010 Málaga

manuelcobodols@yahoo.es

(alternative): mangel.cobo.sspa@juntadeandalucia.es
}

\section{References}

1. Jope EM. The emergence of man: information from protein systems. Philosophical Transactions of the Royal Society of London-Series B: Biological Sciences 1981; 292:121-131.

2. Scriver CR, Lamm P, Clow CL. Plasma amino acids: screening, quantitation, and interpretation. Am J Clin Nutr 1971; 24:876-890.

3. Frommel C. The apolar surface area of amino acids and its empirical correlation with hydrophobic free energy. J Theor Biol 1984; 111:247-260.

4. Lochmuller $\mathrm{CH}$, Souter RW. Chromatographic resolution of enantiomers selective review. J Chromatog 1975; 113:283-302.

5. Fleschmann W. The metabolism of damaged cells and tissues. Cold Spring Harbor Symposia on Cuantitative Biology 1939; 7:290-300.

6. Lanza-Jacoby S, Lansey S, Miller EE, Clearly MP. Sequential changes in the activities of lipoptotein lipase and lipogenic enzymes during tumor growth in rats. Cancer Res 1984; 44:5062-5067.

7. Lundholm K, Bylund AC, Schersten T. Skeletal muscle metabolism in patients with malignant tumor. Eur J Cancer 1976; 12:465-473.

8. Jeevanandam M, Lowry SF, Horowitz GD, Brennan MF. Cancer cachexia and protein metabolism. Lancet 1984; 2:1423-1426.

9. Felig P, Marliss E, Ohman JL, Cahill GF. Amino acid metabolism during prolonged starvation. J Clin Invest 1969; 48:584-594.

10. Holt LE, Snyderman SE, Norton PM, Roiman E, Finch J. The plasma aminogram in kwashiorkor. Lancet 1963; 2:1343-1348.

11. Kern KA, Norton JA. Cancer cachexia. JPEN 1988; 12:286-298.

12. Masiar PJ, Medekova E. The role of serine and glutamine in the metabolism of malignant bone tumors and their significance in the diagnosis and prognosis of bone tumors. Neoplasm; 35:197-206.

13. Watanabe A, Higashi T, Sakata T, Nagashima H. Serum amino acid levels in patients with hepatocelular carcinoma. Cancer 1984; 54:1875-1882.

14. Russell DM, Shike M, Anderson GH. Amino acid metabolism in small cell lung cancer. J Parenter Enteral Nutr 1981; 6:592.

15. Cascino A, Muscaritoli M, Cangiano C, et al. Plasma aminoacid imbalance in patients with lung and breast cancer. Anticancer Res 1995; 15:507-510.

16. Ching N, grossi C, Jham C. Plasma amino acid deficits and the effect of nutritional support in chemotherapy treatment. Surgery 1984; 95:730-737.

17. Tayek JA, Sutter L, Manglik S, Lillington LB, Grosvenor M, Chlebowski RT. Altered metabolism and mortality in patients with colon cancer receiving chemotherapy. Am J Med Sci 1995; 310:48-55. 
18. Nechiporenko NA, Nefedov LI, Klimovich II. The free amino acid content of the blood serum in bladder cancer patients. Urol Nephrol 1990; 5:17-20.

19. Elling D, Bader K, Schicke B. Free serum amino acids in patientts with tumors of different sites - tumor induced imbalances. Zentralbl Gynakol 1987; 109:1023-1032.

20. Kuzer M, Janizewski J, Meguid MM. Amino acid profiles in tumor-bearing and pair-fed nontumor-bearing malnourished rats. Cancer 1988;62:30-34.

21. Carmichael MJ, Clague MB, Keir MH, Johnston IA. Whole body protein turn over, syntesis and breakdown in patient with colorrectal carcinoma. Br J Surg 1980; 67:736-739.

22. Kuzer M, Janizevski J, Meguid MM. Amino acid profiles in tumor-bearing and pair-fed non tumor-bearing malnourished rats. Cancer 1988; 2:30-34.

23. Waterlow JC, Garlick PJ, Millward DJ. Free amino acid in protein turnover in mammalian tissues and in the whole body 1978; 117-176. Amsterdam: Elsevier North Holland.

24. Landel AM, Hammond WG, Meguid MM. Aspects of amino acid and protein metabolism in cancer bearing states. Cancer 1985; 55:230-237.

25. Kubota A, Meguid MM, Hitch DC. Amino acid profiles correlate diagnostically with organ site in three kinds of malignant tumors. Cancer 1992; 69:2343-2348.

26. Rivera S, Lopez Soriano FJ, Azcon Bieto J, Argiles JM. Blood amino acid compartmentation in mice bearing Lewis lung carcinoma. Cancer Res 1987; 47:5644-5646. 